\title{
Soft sensor control of metabolic fluxes in a recombinant Escherichia coli fed-batch cultivation producing green fluorescence protein
}

\author{
Robert Gustavsson and Carl-Fredrik Mandenius
}

\section{Linköping University Post Print}

\section{Tweet}

N.B.: When citing this work, cite the original article.

The original publication is available at www.springerlink.com:

Robert Gustavsson and Carl-Fredrik Mandenius, Soft sensor control of metabolic fluxes in a recombinant Escherichia coli fed-batch cultivation producing green fluorescence protein, 2013, Bioprocess and biosystems engineering (Print), (36), 10, 1375-1384.

http://dx.doi.org/10.1007/s00449-012-0840-Z

Copyright: Springer Verlag (Germany)

http://www.springerlink.com/?MUD=MP 


\title{
Soft sensor control of metabolic fluxes in a recombinant Escherichia coli fed-batch cultivation producing Green Fluorescence Protein
}

\author{
Robert Gustavsson, Carl-Fredrik Mandenius \\ Division of Biotechnology/IFM, Linköping University, 58183 Linköping, Sweden
}

\begin{abstract}
A soft sensor approach is described for controlling metabolic overflow from mixed acid fermentation and glucose overflow metabolism in a fed-batch cultivation for production of recombinant green fluorescence protein (GFP) in Escherichia coli. The hardware part of the sensor consisted of a near-infrared in situ probe that monitored the $E$. coli biomass and an HPLC analyzer equipped with a filtration unit that measured the overflow metabolites. The computational part of the soft sensor used basic kinetic equations and summations for estimation of specific rates and total metabolite concentrations. Two control strategies for media feeding of the fed-batch cultivation were evaluated: (1) controlling the specific rates of overflow metabolism and mixed acid fermentation metabolites at a fixed pre-set target values, and (2) controlling the concentration of the sum of these metabolites at a set level. The results indicate that the latter strategy was more efficient for maintaining a high titer and low variability of the produced recombinant GFP protein.
\end{abstract}

Keywords:

Soft sensors; Software sensors; Bioprocess monitoring and control; Fed-batch cultivation control; Overflow metabolism; Mixed-acid fermentation; 


\section{Introduction}

A soft sensor (or software sensor) utilizes one or several hardware sensor signals with mathematical models for acquiring on-line process data that cannot easily be measured in real time [1-3]. A variety of combinations of soft sensor is reported for process monitoring and control applications in industry [4-7]. During the past ten years, the soft sensors have also extensively been discussed in biotechnology, in particular for the monitoring and control of bioreactors [8-14]. Biomass growth, for example, has been estimated by soft sensors based on base titration [15, 16], absorbance measurement [11], and exhaust gas analysis [12] using mechanistic models. Other soft sensors have used regression models, multivariate models, and neural networks [17] in combination with on-line fluorimetry [18] and multisensor arrays [19].

A few studies describe soft sensors for feedback control purposes in biotechnology. In pharmaceutical processing this has concerned e.g. production of antibiotics [10]. In microbial processes, examples include feedback control of specific growth rate from gas mass balance $[11,12]$ and monitoring of oxygen and carbon dioxide gases for estimating biomass on-line [20-22]. In other studies the soft sensors have controlled the nutrient feeding to the fed-batch by monitoring key metabolites as acetate by on-line HPLC [11]. These results show that feedback control could be used successfully to effectively adjust the feed profile, thereby maximizing the feeding rate and minimizing the culture time as well as stabilizing the product yield. Moreover, the results can be extrapolated to other production organisms and product proteins.

The soft sensor concept is in good compliance with the essence of the PAT principles, i.e. using on-line monitoring and control to reduce process variability and by that reduce discarded batches and lower total manufactured volumes of a product [23]. This includes biopharmaceuticals such as recombinant proteins, vaccines and gene therapy vectors [20].

In this article, the soft sensor concept is applied to monitoring and control of the production of a recombinant protein. As host-vector has been chosen the expression of the Green Fluorescent Protein (GFP) in E. coli, since it represents a typical biopharmaceutical protein 
production system [24]. A previous study of this system by us [11] is here extended to include control of glucose overflow and MAF metabolites [25-27]. In order to simplify the control only one variable is controlled, namely the sum of the detectable metabolites. This is based on the reasoning that it is the total flux of the glycolytic pathway that should be modulated in order to stabilize the final product protein titer; an idea that previously has been proposed by other researchers $[25,28]$. 


\section{Materials and Methods}

\section{Cell culture and media}

Escherichia coli strain HMS 174(DE3)(Novagen, Madison, WI, USA) transformed with plasmid pET30a (Novagen) containing GFP-mut3.1 (Clontech, US), under control of the T7/lac promoter and a $25 \mathrm{bp} \mathrm{lac}$ operator sequence was used. The transformed strain was obtained from the Department of Biotechnology, University of Natural Resources and Life Science, Vienna.

A semi-synthetic medium described by Nemecek et al [29] was used for the pre-culture while a modified medium was used in the fed-batch cultivation. All reagents and chemicals were purchased from Merck, if not otherwise stated. Media components were added in relation to the working volume of the bioreactor. The pre-culture medium was composed of $3.0 \mathrm{~g} \mathrm{~L}^{-}$

${ }^{1} \mathrm{KH}_{2} \mathrm{PO}_{4}, 4.5 \mathrm{~g} \mathrm{~L}^{-1} \mathrm{~K}_{2} \mathrm{HPO}_{4} \cdot 3 \mathrm{H}_{2} \mathrm{O}, 2.5 \mathrm{~g} \mathrm{~L}^{-1} \mathrm{C}_{6} \mathrm{H}_{5} \mathrm{Na}_{3} \mathrm{O}_{7} \cdot 2 \mathrm{H}_{2} \mathrm{O}, 1.0 \mathrm{~g} \mathrm{~L}^{-1} \mathrm{MgSO}_{4} \cdot 7 \mathrm{H}_{2} \mathrm{O}, 4.5 \mathrm{~g}$ $\mathrm{L}^{-1}\left(\mathrm{NH}_{4}\right)_{2} \mathrm{SO}_{4}, 3.7 \mathrm{~g} \mathrm{~L}^{-1} \mathrm{NH}_{4} \mathrm{Cl}, 1.5 \mathrm{~g} \mathrm{~L}^{-1}$ yeast extract, $6.0 \mathrm{~g} \mathrm{~L}^{-1}$ glucose and $0.5 \mathrm{~mL} \mathrm{~L}^{-1}$ of a trace element solution. The batch medium was composed of $5.0 \mathrm{~g} \mathrm{~L}^{-1}$ glucose, $6.67 \mathrm{~g} \mathrm{~L}^{-1} \mathrm{~K}_{2} \mathrm{HPO}_{4}$, $0.25 \mathrm{~g} \mathrm{~L}^{-1} \mathrm{KH}_{2} \mathrm{PO}_{4}, 1.2 \mathrm{~g} \mathrm{~L}^{-1} \mathrm{NaCl}, 1.1 \mathrm{~g} \mathrm{~L}^{-1} \mathrm{~K}_{2} \mathrm{SO}_{4}, 0.5 \mathrm{~g} \mathrm{~L}^{-1}$ yeast extract, $10 \mathrm{~g} \mathrm{~L}^{-1}\left(\mathrm{NH}_{4}\right)_{2} \mathrm{SO}_{4}, 0.15$ $\mathrm{g} \mathrm{L}^{-1} \mathrm{MgSO}_{4} \cdot 7 \mathrm{H}_{2} \mathrm{O}, 0.013 \mathrm{~g} \mathrm{~L}^{-1} \mathrm{CaCl}_{2} \cdot 2 \mathrm{H}_{2} \mathrm{O}$ and $0.125 \mathrm{~mL} \mathrm{~L}^{-1}$ of the trace element solution, and the feed medium was composed of $100 \mathrm{~g} \mathrm{~L}^{-1}$ glucose, $27.5 \mathrm{~g} \mathrm{~L}^{-1}\left(\mathrm{NH}_{4}\right)_{2} \mathrm{SO}_{4}, 1.5 \mathrm{~g} \mathrm{~L}^{-}$ ${ }^{1} \mathrm{MgSO}_{4} \cdot 7 \mathrm{H}_{2} \mathrm{O}, 0.026 \mathrm{~g} \mathrm{~L}^{-1} \mathrm{CaCl}_{2} \cdot 2 \mathrm{H}_{2} \mathrm{O}$ and $2.50 \mathrm{~mL} \mathrm{~L}{ }^{-1}$ of the trace element solution. The trace element solution contained $40.0 \mathrm{~g} \mathrm{~L}^{-1} \mathrm{FeSO}_{4} \cdot 7 \mathrm{H}_{2} \mathrm{O}, 10.0 \mathrm{~g} \mathrm{~L}^{-1} \mathrm{MnSO}_{4} \cdot \mathrm{H}_{2} \mathrm{O}, 10.0 \mathrm{~g} \mathrm{~L}^{-}$ ${ }^{1} \mathrm{AlCl}_{3} \cdot 6 \mathrm{H}_{2} \mathrm{O}, 4.0 \mathrm{~g} \mathrm{~L}^{-1} \mathrm{CoCl}_{2}, 2.0 \mathrm{~g} \mathrm{~L}^{-1} \mathrm{ZnSO}_{4} \cdot 7 \mathrm{H}_{2} \mathrm{O}, 2.0 \mathrm{~g} \mathrm{~L}^{-1} \mathrm{Na}_{2} \mathrm{MoO}_{2} \cdot 2 \mathrm{H}_{2} \mathrm{O}, 1.0 \mathrm{~g} \mathrm{~L}^{-1}$ $\mathrm{CuCl}_{2} \cdot 2 \mathrm{H}_{2} \mathrm{O}$ and $0.50 \mathrm{~g} \mathrm{~L}^{-1} \mathrm{H}_{3} \mathrm{BO}_{3}$ dissolved in $5 \mathrm{~N} \mathrm{HCl}$.

\section{Cell bank preparation}

The transformant was cultured in a rotary incubator at $200 \mathrm{rpm}$ overnight at $37{ }^{\circ} \mathrm{C}$. The culture was grown in a shake-flask containing $200 \mathrm{~mL}$ of the semi-synthetic medium supplemented with $50 \mu \mathrm{g} \mathrm{L}^{-1}$ kanamycin and reached a cell concentration of $2 \mathrm{~g}$ dry weight $\mathrm{L}^{-1}$. The optical density at $600 \mathrm{~nm}\left(\mathrm{OD}_{600}\right)$ after $19 \mathrm{~h}$ was approximately 4 absorbance units. Vials 
of aliquots with $1.2 \mathrm{~mL}$ of the cell suspension and $0.6 \mathrm{~mL}$ of glycerol (60\%) were prepared and stored at $-70^{\circ} \mathrm{C}$.

\section{Fed-batch cultivation}

All cultivations were carried out in a $10 \mathrm{~L}$ in situ sterilized bioreactor (Model LMS 2002, Belach Bioteknik AB, Solna, Sweden) equipped with standard instrumentation. The control software (BioPhantom, version 2000; Belach Bioteknik AB) was implemented with the soft sensor algorthims described below. A pre-culture was prepared from one cell bank vial in a shake flask with $200 \mathrm{~mL}$ medium and grown overnight to an OD value of 8-12. This culture was used to inoculate the bioreactor at an initial batch medium volume of $4 \mathrm{~L}$. During the subsequent fed-batch $2 \mathrm{~L}$ of feeding medium was added. The $\mathrm{pH}$ was controlled at $7.0 \pm 0.1$ by addition of $1 \mathrm{M}$ sulfuric acid or $20 \%$ ammonia. The aeration rate was $1 \mathrm{vvm}$ and the temperature was 37 ${ }^{\circ} \mathrm{C}$. Dissolved oxygen (DO) was controlled to $30 \%$ by adjusting of the stirrer speed (300-1200 rpm). Foaming was controlled by addition of a $50 \%$ anti-foam solution (Glanapon, Busetti \& Co $\mathrm{GmbH}$, Vienna, Austria).

Exponential feeding of the fed-batch was started when the DO level increased due to depletion of the batch medium. This was a well-defined starting point which was easy to reproduce. The feeding rate of the feed pump (P4 U1-MXV, Alitea, Sweden) was adjusted so the culture maintained a constant specific growth rate of $0.3 \mathrm{~h}^{-1}$. The rate was calculated from the weight of the medium flask as recorded on-line by a scale (XL-3100, Denver Instrument). A tuned PID-controller adjusted the feed pump speed according to a set growth rate.

GFP expression was induced by addition of $0.03 \mathrm{~g} \mathrm{~L}^{-1}$ isopropyl $\beta$-D-1-thiogalactopyranoside (IPTG) (Sigma) when the $O D_{600}$ had reached a value of 20 absorbance units. This corresponded to approximately one culture generation and occurred 3 to 4 hours after starting of feeding. 


\section{On-line analyzers}

Standard bioreactor devices

The reactor was equipped with standard $\mathrm{DO}$ and $\mathrm{pH}$ electrodes as well as probes for temperature, headspace pressure, and volume level. Signals were acquired every second.

Near-infrared (NIR) monitoring

Biomass was measured at $900-1100 \mathrm{~nm}$ by a sterilizable in situ near-infrared probe (Cell Growth Monitor Model 650; Wedgewood Technology, CA). The probe used a pathlength of 5 $\mathrm{mm}$. The NIR signal was filtered to reduce noise, and the sensitivity could be adjusted by nonlinear compensation. The probe was inserted close to the stirrer turbine of the bioreactor to ensure that the measurement channel of the probe was efficiently flushed with culture media. Other signal disturbances due to changes in flow pattern caused by impeller rate adjustments were compensated for by a filter function implemented the instrument [11].

\section{On-line high performance liquid chromatography (HPLC)}

Continuous sampling of culture media was carried out using an in situ filtration probe (FISPsampling probe, Flownamics, Madison, US). Culture sample stream was pumped from the filtration probe by a peristaltic pump to an automatic valve and injected into an HPLC system (Shimadzu, Tokyo, Japan). An ion-exclusion resin (Aminex ${ }^{\circledR} \mathrm{HPX}-87 \mathrm{H}, 300 \times 7.8 \mathrm{~mm}$; BioRad) placed in a column oven (60 ${ }^{\circ} \mathrm{C}$; CTO-20A) analyzed organic acids, alcohols and carbohydrates in the media samples using a refractive index detector (RID-10A). The mobile phase was $5 \mathrm{mM}$ sulfuric acid. A guard column (125-0129, BioRad) protected the analytical column from impurities. Measurements were performed every 20 min. 
Off-line analyses

Samples for measurement of optical density $\left(\mathrm{OD}_{600}\right)$ and the biomass dry weight were taken from the bioreactor intermittently through a steamed pipe. GFP fluorescence was measured in a fluorimeter (Fluostar Galaxy, BMG Labtechnologies $\mathrm{GmbH}$, Offenburg, Germany) at excitation/emission wavelengths of $470 / 515 \mathrm{~nm}$ in 1-mL samples. As reference was used uninduced culture media.

\section{Soft sensor models}

\section{Biomass}

Biomass concentration was estimated from the absorbance signal $\left(A_{N I R}\right)$ of the NIR probe. The absorbance was influence by those optical properties of the culture medium that caused absorbance in the 900-1100 nm range, including cell particles, debris, and air bubbles. To compensate for and filter out noise related to air bubbles and to reduce non-linearity of the signal a first-order linearization was carried out by the NIR probe instrument. A calibration factor $\left(K_{N I R}\right)$ in the soft sensor model converted the NIR signal to biomass concentration $\left(\mathrm{g} \mathrm{L}^{-1}\right)$ : $X_{N I R}=K_{N I R} A_{N I R}$

The calibration factor was verified in repeated cultivations.

Sum of concentration of mixed acids fermentation and overflow metabolites

The concentration of each metabolite (acetate, lactate, formate, ethanol) was calculated by the HPLC software. The concentration values were summarized into a new parameter according to:

$c_{M}=c_{\text {acetate }}+c_{\text {lactate }}+c_{\text {formate }}+c_{\text {ethanol }}$ 


\section{Specific production rate of mixed acid fermentation and overflow metabolites}

The specific production rate of the metabolites was calculated from HPLC data according to:

$$
q_{M}=\frac{d c_{M}}{d t} \frac{1}{X_{N I R}}
$$

The data were generated on-line via the HPLC software (LCsolution software, Shimadzu, Tokyo, Japan) from a shared network folder according to a pre-set schedule. Data files with the HPLCderived concentration values for the metabolites were updated every 20 min. This interval $\left(t_{n}\right.$, $t_{n-1}$ ) was also used in the calculation of the volumetric rate:

$$
r_{M}=\frac{C_{M, n}-C_{M, n-1}}{t_{n}-t_{n-1}}
$$

and in the calculation of the specific rate:

$$
q_{M}=\frac{r_{M}}{X_{N I R}}
$$

\section{Feedback controller}

The feedback controller was based on the following equations:

$e(t)=\frac{(S p-P v)}{300} \cdot 100 \%$

$u(t)=K_{P} \cdot e(t)$

$Y_{2}(s)=u(t) \cdot F r$

$Y(s)=Y_{1}(s)+Y_{2}(s)$

Once the process variable $P V\left(c_{M}\right.$ or $\left.q_{M}\right)$ was acquired by the sensor and the set-point $S p$ and $K_{\mathrm{P}}$ parameters were entered, the controller was activated. Then the controller calculated the scaled error $(e(t))$. The $u(t)$ was calculated proportional to the $e(t)$. When $e(t)$ was 0 the $u(t)$ was set to 0 . Otherwise, depending on the $e(t)$, the $u(t)$ was set to $(-50 \%$ to $+50 \%)$ of the feed 
pump range $(-400$ to $+400 \mathrm{~g} / \mathrm{h})$. The resulting $Y_{2}(\mathrm{~s})$ was added to the actual output of the preset profile $\left(Y_{1}(s)\right)$. 


\section{Results and Discussion}

The control strategy used in this study was based on the idea that the accumulation of metabolites from glucose overflow and MAF metabolism in E. coli should be maintained at a low level. The causes of the metabolite accumulation are either overflow metabolism resulting in the accumulation of acetate as an effect of saturation of the Krebs' cycle, or mixed acid fermentation, resulting in accumulation of metabolites coupled to the glycolysis as an effect of oxygen depletion. Figure 1 provides a schematic overview of the glucose overflow and mixed acid fermentation metabolism in $E$. coli showing the pathways involved in the metabolite accumulation.

It has previously been suggested [30] that fed-batch cultivations should benefit from been controlled in such a way that the metabolic fluxes in the individual cell are constant and low. This has been referred to as physiological control [30]. It requires that the cell concentration of the culture is monitored on-line and that the key metabolites involved are monitored simultaneously.

Other studies [25-27] suggest that metabolites resulting from mixed acid fermentation have a similar influence on an E. coli culture.

The above cited reports also support that heterologous protein expression in $E$. coli is facilitated by controlling the E. coli metabolism according to these premises [28].

These rationales have motivated the two control approaches applied in this study, i.e. using soft sensor based physiology control from the on-line monitoring of metabolites and biomass (Fig. 2).

\section{Cultivation of the fed-batch using feed-forward feeding of the medium}

As reference, a cultivation was first carried out with a feed-forward control of the feeding based on a pre-set feeding profile. Thus, any adaptions to changing or unpredicted variations of the levels of the MAF or overflow metabolites were not possible. 
The cultivation was carried out according to a typical fed-batch protocol; after inoculation a batch phase was run until the batch medium was depleted and the biomass had reached a level suitable for starting the feeding. The soft sensor estimation of biomass, glucose and MAF metabolites were monitored with a delay of $20 \mathrm{~min}$. The culture in the fed-batch was induced after approximately one generation by a pulse of inducer (IPTG). The amount of inducer was estimated from a previous study with the same host-vector system [31]. The expression of GFP was determined by off-line measurements [32].

Figure 3 compares two fed-batch cultivations carried out under identical conditions. Although an identical feeding regime was applied in both fed-batch cultivations, the GFP concentration differed considerably (2700 and $3700 \mathrm{rfu}$, i.e. \pm 30\%) five hours after induction while the biomass had almost the same concentration $\left(10 \mathrm{~g} \mathrm{~L}^{-1}\right)$. This variability shown was not unexpected. Previous reports with E. coli producing recombinant proteins have also shown significant variability under identical or similar culture conditions. For example, in a study by Lübbert and coworkers [12] a batch-to-batch variability of protein expression of $\pm 25 \%$ five hours after induction was shown. This is on the same level as in observed here.

Thus, the observations described above indicate that a control approach where the conditions are maintained more accurately would be motivated.

\section{Feedback control using the sum of specific production rates of the metabolites as set-point}

In a first attempt to reduce the variability of the GFP production, the specific metabolic rates of the production of MAF metabolites was feedback controlled using a constant set-point of rate of the total MAF metabolite formation. Thus, the rate of feeding adjusted repeatedly a predetermined feed rate profile calculated as the feed-forward profile used above (Fig. 2A).

The control error, i.e. the difference between the $q_{M}$ set-point value and the soft sensor estimate of $q_{\mathrm{M}}$ was used in a standard P-controller algorithm. The chosen $K_{\mathrm{P}}$ value determined the control action, i.e. the change of feed rate of the feeding. A new value was recalculated every 20 or $25 \mathrm{~min}$. 
The delay of the soft sensor was caused by the retention time in the chromatography column. Each chromatogram covered 5 peaks (glucose and four key metabolites) where the individual peak areas were integrated in the software. Thus, the last eluted metabolite determined the delay time. Moreover, the sampling from the bioreactor, the pumping of the sample stream to the HPLC valve, extended the delay time further. Faster sampling flow could have shortened the delay and a faster elution rate could have shortened the elution of the column. However, this would have resulted in a higher consumption of reactor medium and a shorter life span of the HPLC column. Despite this delay, the feedback P-controller was able to perform the control with a relatively minor degree of oscillation.

Figure 4 compares three cultivations with a set-point of $q_{\mathrm{M}}$ of $0.15 \mathrm{~g} \mathrm{~g}^{-1} \mathrm{~h}^{-1}$ and a $K_{\mathrm{P}}$ of 100 . The variability of GFP was relatively high; seven hours after induction the GFP concentration varied $\pm 15 \%$ (of 2800 to $3800 \mathrm{rfu}$ ).

The setting of the control parameters was the result of a four preceding fed-batch cultivations where the controller was tuned and different specific rates assessed.

The P-controller showed ability to minimize the variability of GFP production compared to the feed-forward control as showed in Figure 3, although not as much as intended.

However, the production levels of MAF metabolites were unexpectedly high and inconsistent. Thus, the purpose with the control strategy, to maintain the flux of the metabolism of acids during the feeding phase, was apparently not sufficiently successful.

This may have been due to several reasons. The starting condition of the inocculum varied between the runs. The amounts of accumulated acids that were formed during the uncontrolled batch phase showed varying profiles for each acid. At the onset of feeding the selected specific rate did not led to a re-assimilation of metabolites.

The NIR probe, which sometimes showed a reduced precision, may have biased the estimation of the specific production rate value. The cause of the variation was mainly due to a varying sensitivity to aeration rate in the bioreactor. 
Thus, the findings suggested that an alternative control strategy was worthwhile to investigate.

\section{Feedback control using the sum of concentrations of the produced metabolites as set-point}

This, an alternative control strategy was tried where the sum of the concentrations of the MAF metabolites, $c_{M}$, was used as set-point of the P-controller. This simplifies the soft sensor structure since the biomass signal from the NIR probe is not required (Fig. 2B). If the NIR probe introduced non-linear effects and are not sufficiently compensated for, this would not influence the control.

Four test cultivations were carried out in order to select the set-point value and to tune the $K_{\mathrm{P}}$

value of the controller. Values in the concentration range of 0.1 to $0.5 \mathrm{~g} \mathrm{~L}^{-1}$ with $K_{\mathrm{P}}$ values in the range 1-70 were compared.

Figure 5 shows three cultivations, all controlled with identical set-point $(0.5)$ and $K_{P}(70)$ values. As seen, the GFP expression profiles after the induction at one generation show a higher coherence than was observed in the specific rate controller case. The variability of the GFP fluorescence after five to six hours was $\pm 7 \%$ (3400-3900 rfu).

After an initial control action phase the sum of MAF metabolite concentrations reached an average value of $0.5 \mathrm{~g} \mathrm{~L}^{-1}$ in the three cultivations (Fig 6). Individual metabolites showed similar profiles as the summation value except for acetate. The on-line HPLC data revealed that acetate was readily re-assimilated while the MAF metabolites tended to accumulate in the medium due to their slow or absence of re-assimilation.

The MAF metabolite profiles observed were stable and followed the intended course during the fed-batch phase. This was an improvement from the $q_{M}$ control strategy (cf. Fig. 4, lower panels).

Especially this latter soft sensor provided a useful sensor tool that supports the intention with the PAT initiative $[12,23]$. It shows that soft sensor based control is advantageous and can contribute to collect more data using on-line monitoring in combination with relatively 
uncomplicated mathematical modeling. The number of alternative soft sensor solutions that can exploit the same approach is significant [3].

The effect of this control strategy was significantly better than when controlling the $q_{\mathrm{M}}$. The variation in final biomass concentration was improved with the $c_{M}$ strategy $( \pm 17.4 \%$ to $\pm 1.8 \%)$, and the variation in GFP decreased significantly when using $c_{M}$ as controlled variable $( \pm 14.4 \%$ to $\pm 7.4 \%)$.

\section{Conclusion}

Different strategies for performing fully automated and observable processes based on soft sensor approaches have previously been investigated [4, 33, 34]. Mathematical modeling alone for prediction of growth and other metabolic activity of the cells is a resourceful strategy but has the drawback that the variability of the complex biological systems makes accurately predictions difficult. The combination of on-line based monitoring and control that becomes attainable with the soft sensor approach has therefore a significant advantage of being able to compensate for deviations in the metabolism of the cells and allowing regulation according to the momentaneous conditions in the cultivation [3].

The presented study shows how the variability of a recombinant protein product can be reduced by soft sensor based control. The soft sensor reduces the need for instrumentation and off-line analysis. The main PAT objective, to increase the process stability and reduce the variability of key process parameters, in particular to product titer, can be accomplished with the soft sensor approach.

Furthermore, it can be noted that the controller must not be very precise (i.e. show short declination, minor stationary fault) to actually accomplish low variability. Moreover, the result of the study indicates that the physiological control approach is not necessarily the most successful control strategy. 
However, further simplification of the soft sensor configuration would be desirable. If a lesser number of hardware sensors can accomplish the control strategy, the industrial applicability would be enhanced and maintenance and supply further reduced.

\section{Acknowledgement}

The authors would like to thank Gerald Striedner and Karl Bayer at Universität für Bodenkultur, Vienna, for valuable advice, Maria Carlsson for skillful technical assistance, György Rajkai, Belach $A B$ for valuable contributions with software development, and Linköping University for financial support. 


\section{References}

[1] Chéruy A (1997) Software sensors in bioprocess engineering. J Biotechnol 52:193-199

[2] Lin B, Recke B, Knudsen JKH, Jorgensen SB (2007) A systematic approach for soft sensor development. Comp Chem Eng 31:419-425

[3] Luttmann R, Bracewell DG, Cornelissen G, Gernaey KV, Glassey J, Hass VC, Kaiser C, Preusse C, Striedner G, Mandenius CF (2012) Soft sensors in bioprocesses. Biotechnol J in press

[4] Kadlec P, Gabrys B, Strandt S, et al, (2009) Data-driven soft sensors in the process industry. Comput Chem Eng 33:795-814

[5] Zamprogna E, Barolo M, Seborg DE (2004) Development of a soft sensor for a batch distillation column using linear and nonlinear PLS regression techniques. Contr Eng Pract 12:917-929

[6] Fortuna L, Graziani S, Xibilia MG (2005) Soft sensors for product quality monitoring in debutanizer distillation columns. Contr Eng Pract 13:499-508

[7] Ward AJ, Hobbs PJ, Holliman PJ, Jones DL (2011) Evaluation of near infrared spectroscopy and software sensor methods for determination of total alkalinity in anaerobic digesters. Bioresource Technol 102:4083-4090

[8] Montague GA, Morris AJ, Tham MT (1992) Enhancing bioprocess operability with generic software sensors. J Biotechnol 25:183-201

[9] Linko S, Zhu YH, Linko P (1999) Applying neural networks as software sensors for enzyme engineering. Trend Biotechnol 17:155-162

[10] Arauzo-Bravo MJ, Cano-Izquierdo JM, Gomez-Sanchez E, Lopez-Nieto MJ, Dimitriadis YA, Lopez-Coronado J (2004) Automatization of a penicillin production process with soft sensors and an adaptive controller based on neuro fuzzy systems. Contr Eng Pract $12: 1073-1090$ 
[11] Warth B, Rajkai G, Mandenius CF (2010) Evaluation of software sensors for on-line estimation of culture conditions in an Escherichia coli cultivation expressing a recombinant protein. J Biotechnol 147:37-45

[12] Gnoth $S$, Jenzsch $M$, Simutis R, Lübbert A. Control of cultivation processes for recombinant protein production: a review. Bioprocess. Biosyst. Eng. (2008) 31:21-39

[13] Chen L. Z., Nguang S. K., Li X. M., Chen X. D., Soft sensors for on-line biomass measurements. Bioproc. Biosys. Eng. 2004, 26, 191-195

[14] Kiviharju K., Salonen K., Moilanen U., Eerikäinen T., Biomass measurement online: the performance of in situ measurements and software sensors. J. Ind. Microbiol. Biotechnol. 2008, 35, 657-665

[15] Hoffmann F, Schmidt M, Rinas U (2000) Simple technique for simultaneous on-line estimation of biomass and acetate from base consumption and conductivity measurements in high-cell density cultures of Escherichia coli. Biotechnol Bioeng $70: 358-361$

[16] Sundström H, Enfors SO (2008) Software sensors for fermentation processes. Bioprocess Biosyst Eng 31:145-152

[17] Bachinger T, Riese U, Eriksson R, Mandenius CF (2000) Monitoring process states in a production scale $\mathrm{CHO}$ cell cultivation using a chemical multisensor array. J Biotechnol 76:61-71

[18] Ödman P, Lindvald Johansen C, Olsson L, Gernaey KV, Eliasson Lantz A (2009) On-line estimation of biomass, glucose and ethanol in Saccharomyces cerevisiae cultivations using in-situ multi-wavelength fluorescence and software sensors. J Biotechnol 144:102-112

[19] Bachinger T, Mandenius CF (2000) Review: Searching process information in the aroma of cell cultures. Trends Biotechnol 18:494-500 
[20] Fricke J, Pohlmann K, Tatge F, Lang R, Faber B, Luttmann R (2011) A multi-bioreactor system for optimal production of malaria vaccine with Pichia pastoris. Biotechnol J $6: 437-451$

[21] Veloso ACA, Rocha I, Ferreira EC (2009) Monitoring of fed-batch E. coli fermentations with software sensors. Bioproc Biosyst Eng 32:381-388

[22] Jenzsch M, Gnoth S, Kleinschmidt M, Simutis R, Luebbert A (2006) Improving the batch-to-batch reproducibility in microbial cultures during recombinant protein production by guiding the process along a predefined total biomass profile. Bioproc Biosyst Eng 29:315-321

[23] Glassey J, Gernaey KV, Oliveria R, Striedner G, Clemens C, Schultz TV, Mandenius CF (2011) PAT for biopharmaceuticals. Biotechnol J 6, 369-377

[24] Mandenius CF, Graumann K, Schultz TW, Premsteller A, Olsson IM, Periot E, Clemens C, Welin M (2009) Quality-by-Design (QbD) for biotechnology-related pharmaceuticals. Biotechnol J 4:600-609

[25] Xu B, Jahic M, Blomsten G, Enfors SO (1999) Glucose overflow metabolism and mixedacid fermentation in aerobic large-scale fed-batch processes with Escherichia coli. Appl Microbiol Biotechnol 51:564-571

[26] Lara AR, Leal L, Flores N, Gosset G, Bolivar F, Ramirez OT (2006) Transcriptional and metabolic response of recombinant $E$. coli to spatial dissolved oxygen tension gradients simulated in a scale-down system. Biotechnol Bioeng 93:272-285

[27] Lara AR, Vazquez-Limon C, Gosset G, Bolivar F, Lopez-Munguia,A, Ramirez OT (2006) Engineering $E$. coli to improve culture performance and reduce formation of byproducts during recombinant protein production under transient intermittent anaerobic conditions. Dissolved oxygen tension gradients simulated in a scale-down system. Biotechnol Bioeng 94:1164-1175

[28] Babu KR, Swaminathan S, Marten S, Khanna N, Rinas U (2000) Production of interferon- $\alpha$ in high cell density cultures of recombinant Escherichia coli and its single 
step purification from refolded inclusion body proteins. Appl Microbiol Biotechnol $53: 655-660$

[29] Nemecek S, Marisch K, Juric R. Bayer K (2008) Design of transcriptional fusions of stress sensitive promoters and GFP to monitor the overburden of Escherichia coli hosts during recombinant protein production. Bioproc Biosyst Eng 31:47-53

[30] Konstantinov KB (1996) Monitoring and control of the physiological state of cell cultures. Biotechnol Bioeng 52:271-289

[31] Vostiar I, Tkac J, Mandenius CF (2004) Off-line monitoring of bacterial stress response during recombinant protein production using an optical biosensor. J Biotechnol 111:191-201

[32] Reischer H, Schotola I, Striedner G, Pötschacher F, Bayer K. (2004) Evaluation of the GFP signal and its aptitude for novel on-line monitoring strategies of recombinant fermentation processes. J Biotechnol 108:115-125

[33] Chen R, John J, Rode B, Hitzmann B, Gerardy-Schahn R, Kasper C, Scheper T (2011) Comparison of polysialic acid production in Escherichia coli $\mathrm{K} 1$ during batch cultivation and fed-batch cultivation applying two different control strategies. J Biotechnol $154: 222-229$

[34] Mandenius CF (2004) Recent developments in the monitoring, modeling and control of biological production systems. Bioproc Biosyst Eng 26:347-351 


\section{Figure legends}

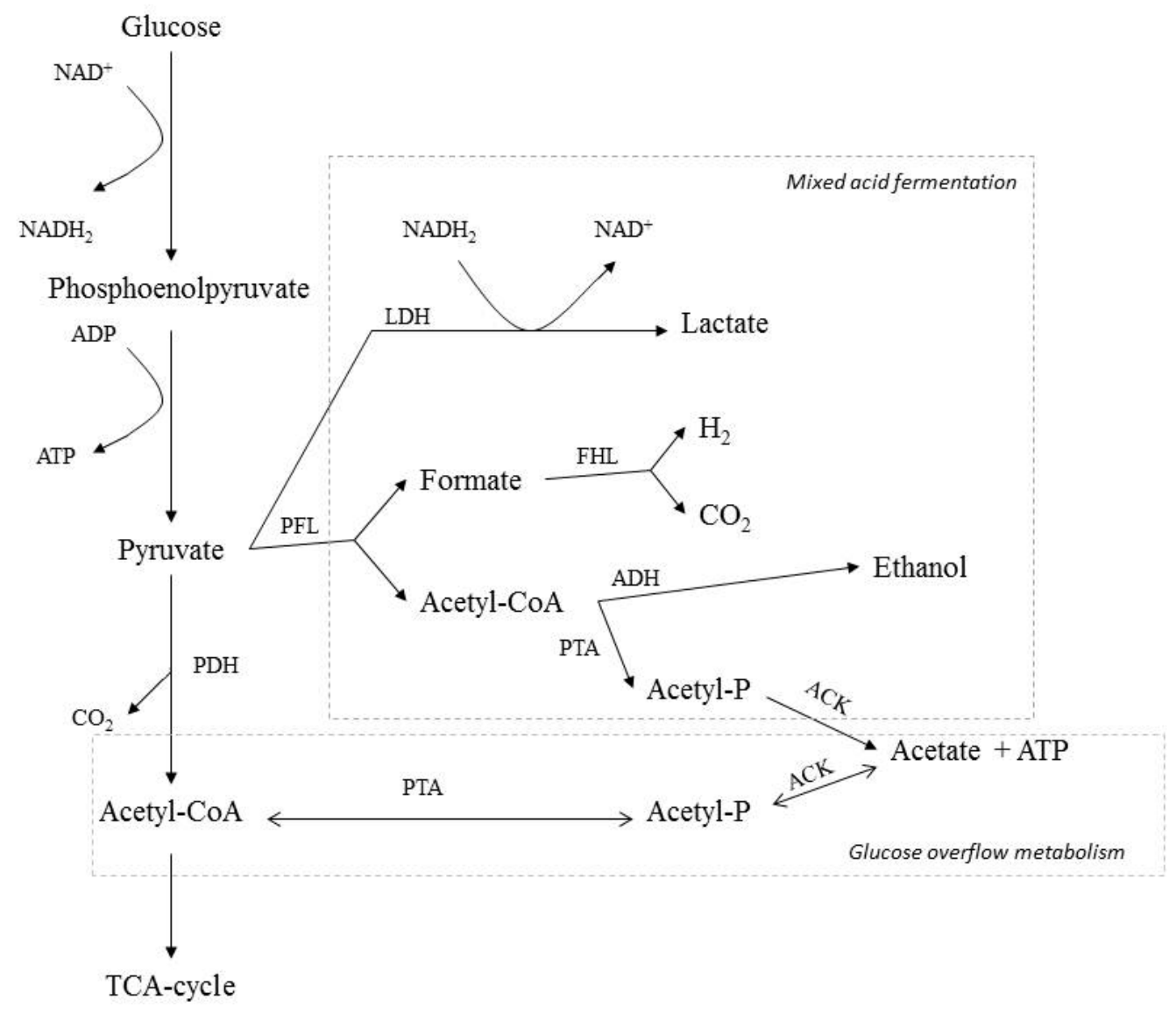

Figure 1

Mixed acid fermentation and glucose overflow metabolism in E. coli are shown in the scheme. The basis for the control strategies applied with the soft sensors was to limit the overproduction of the four main metabolites shown in map. 

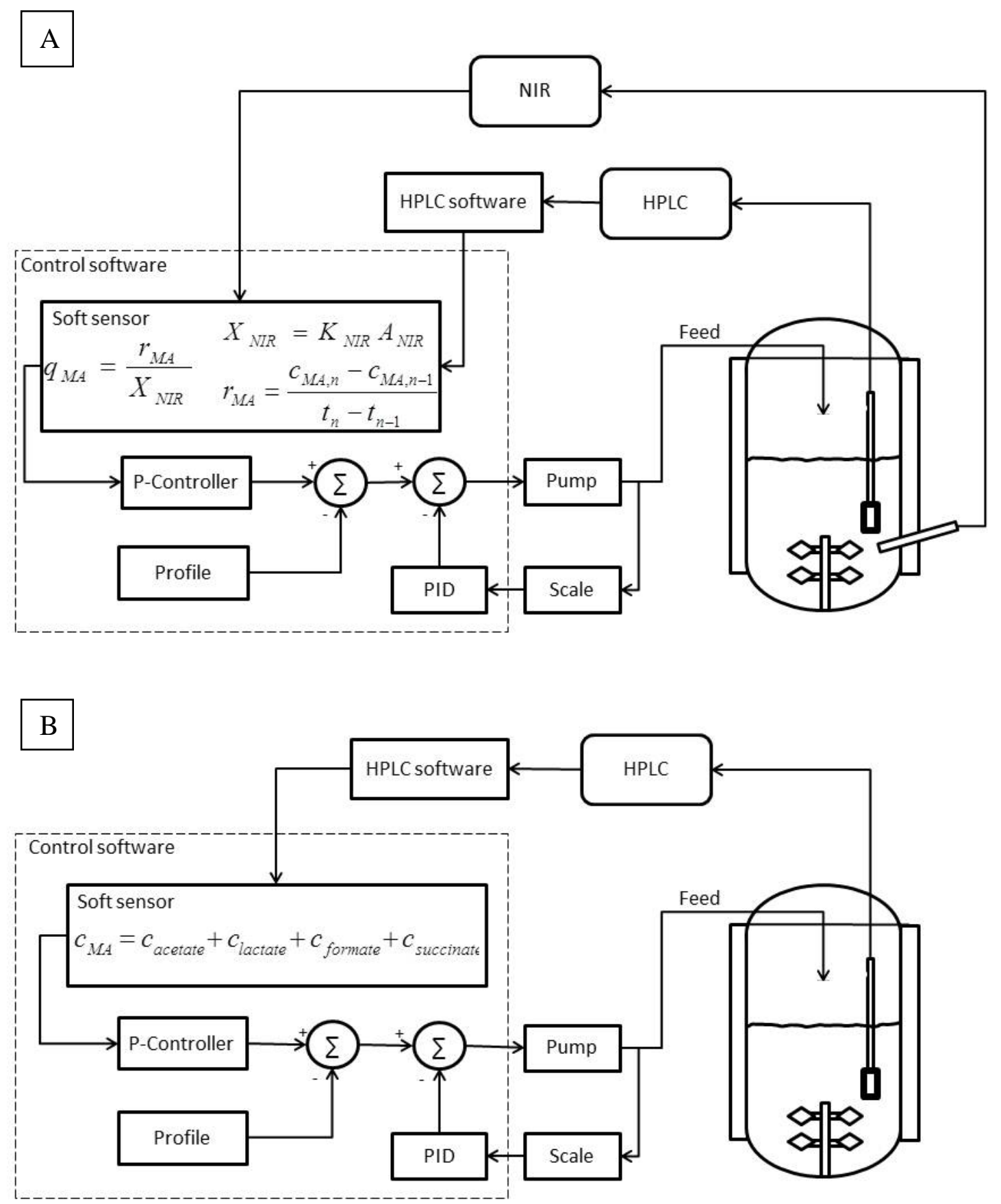

Figure 2

Two soft sensor control strategies of the feeding of the fed-batch cultivation were applied using the sum of specific production rates of the metabolites acetate, lactate, ethanol and formate (Scheme A) or the sum of concentrations of the same acids (Scheme B). 


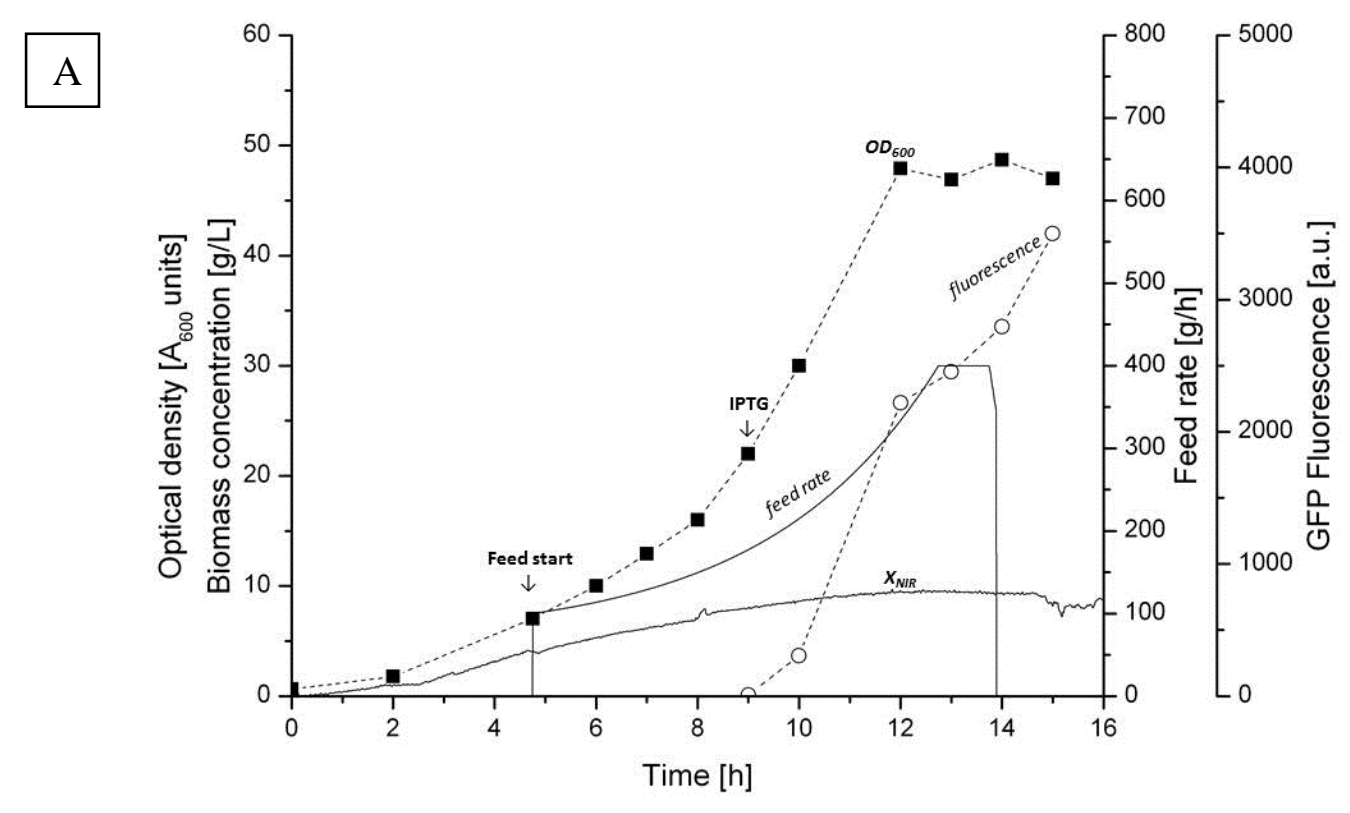

$\mathrm{B}$

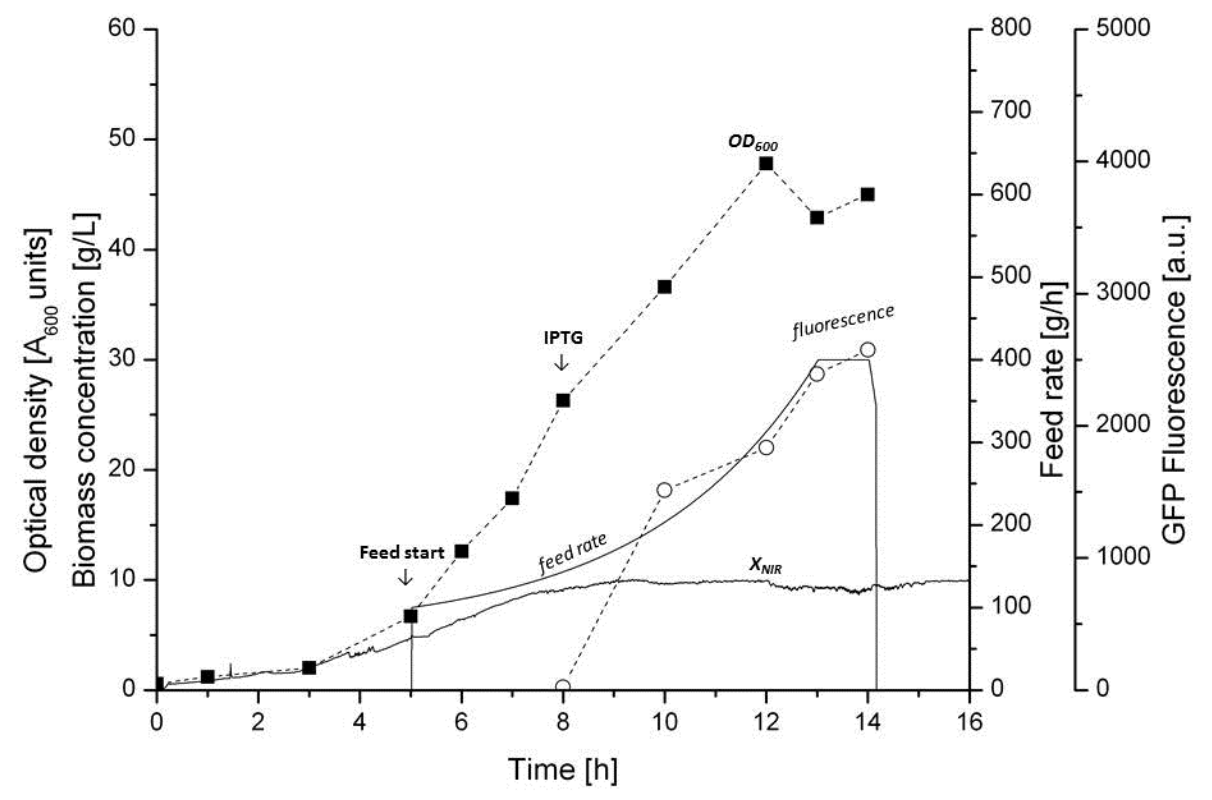

Figure 3

Two identical fed-batch cultivations ( $A$ and $B$ ) where the feeding followed a pre-set feed profile starting at $5 \mathrm{~h}$ and calculated from a defined $\mu$ value. Feeding starts at $5 \mathrm{~h}$ and induction is carried out at 8-9 $\mathrm{h}$ using $0.03 \mathrm{~g} \mathrm{~L}^{-1}$ IPTG. 
A

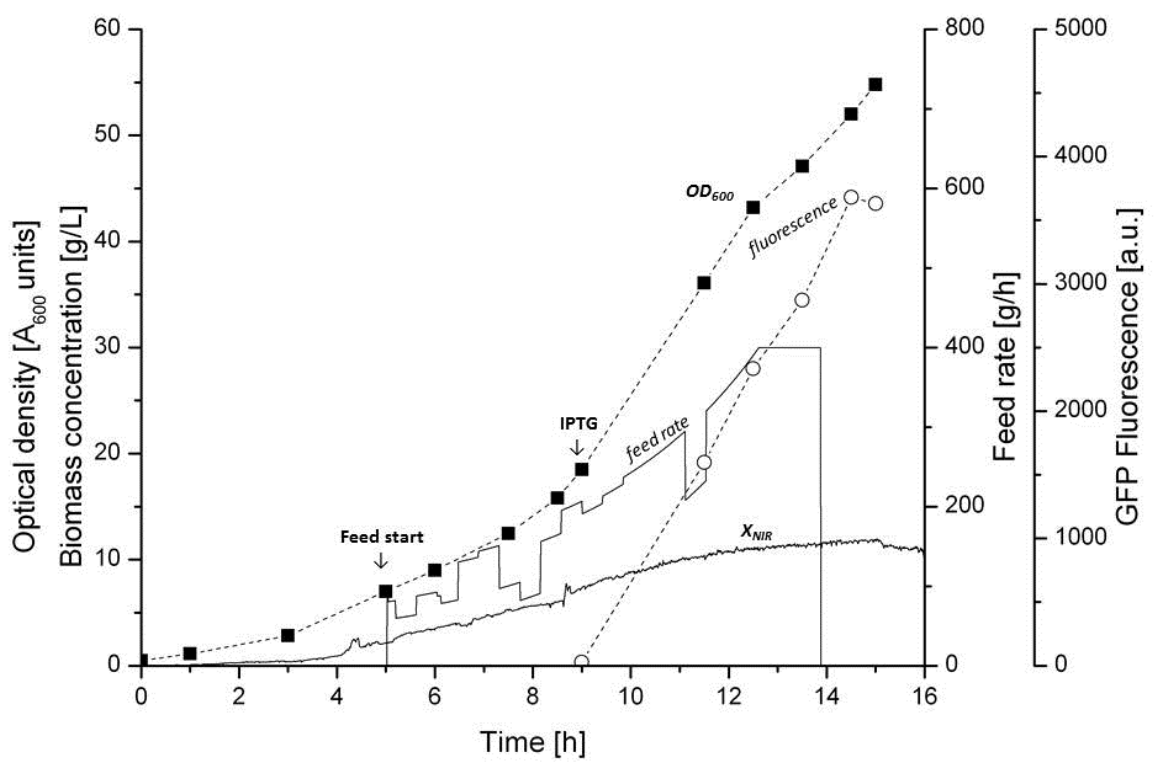

B

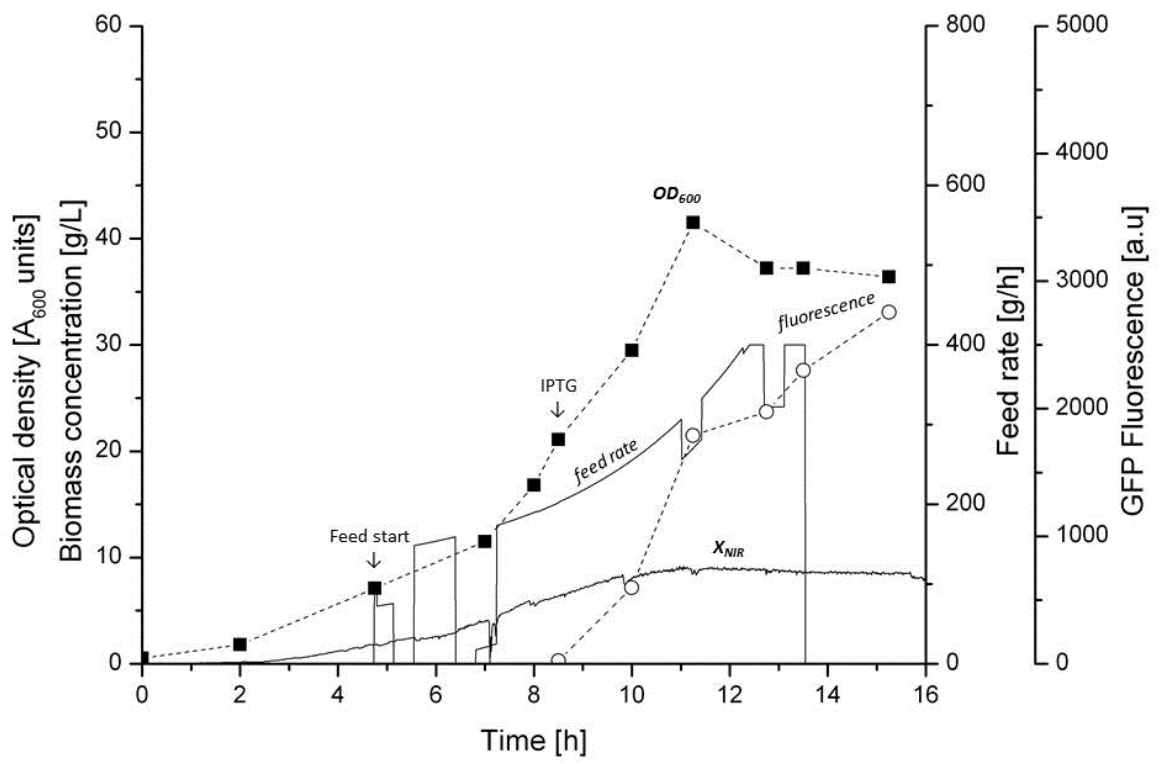




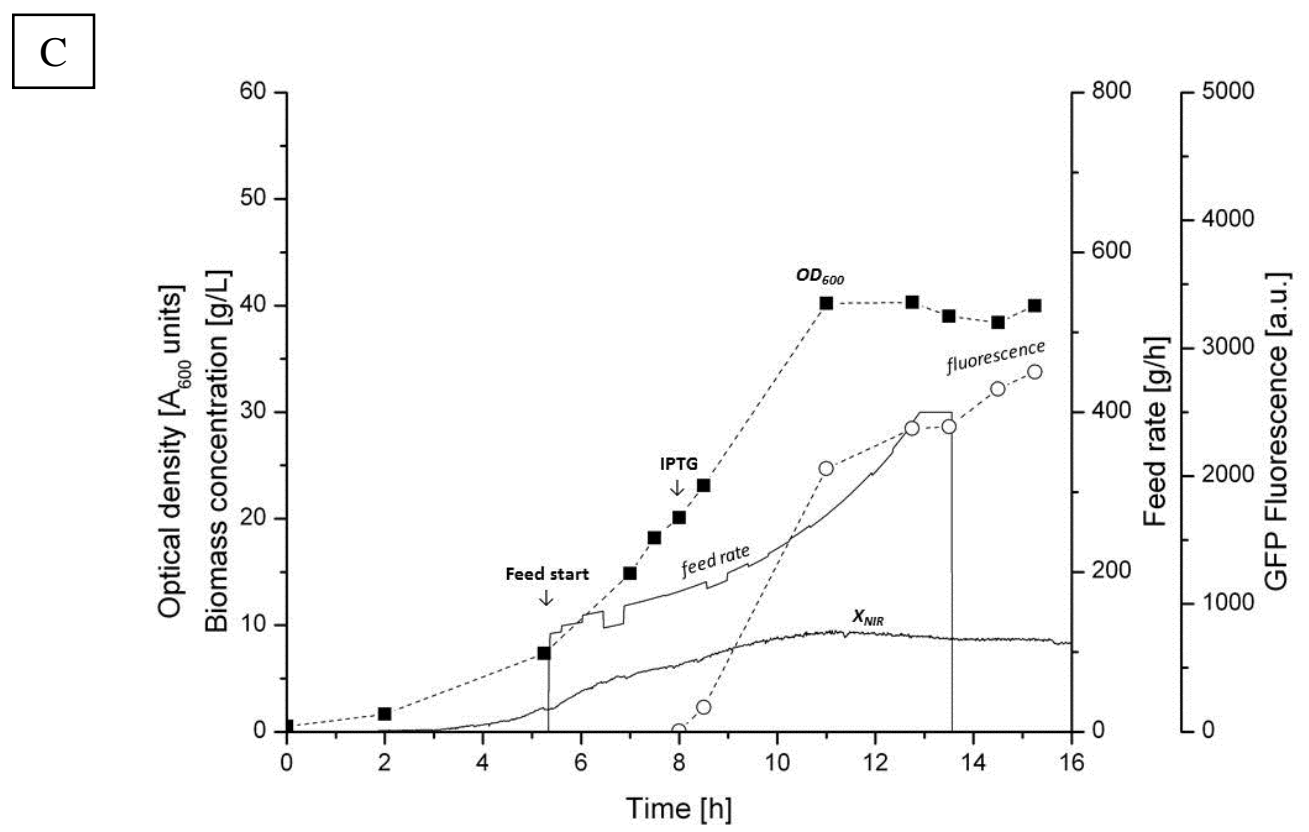

Figure 4

(A) (B) and (C) show three GFP cultivations with control of specific production rates of the sum of MAF metabolites. Feeding starts at $5 \mathrm{~h}$ and induction is carried out at 8-9 $\mathrm{h}$ using $0.03 \mathrm{~g} \mathrm{~L}^{-1}$ IPTG. The upper panels show biomass, GFP and feed rate. The lower panels show the sum of concentration of the MFA metabolites. 
A

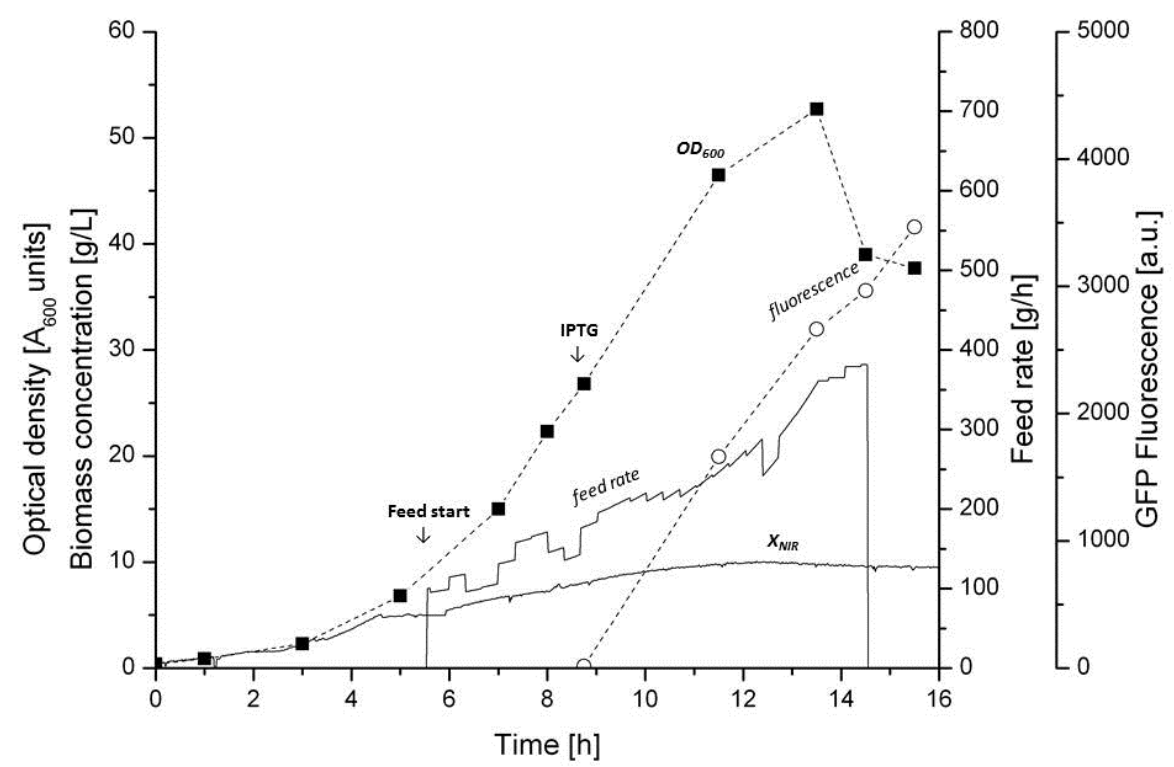

B

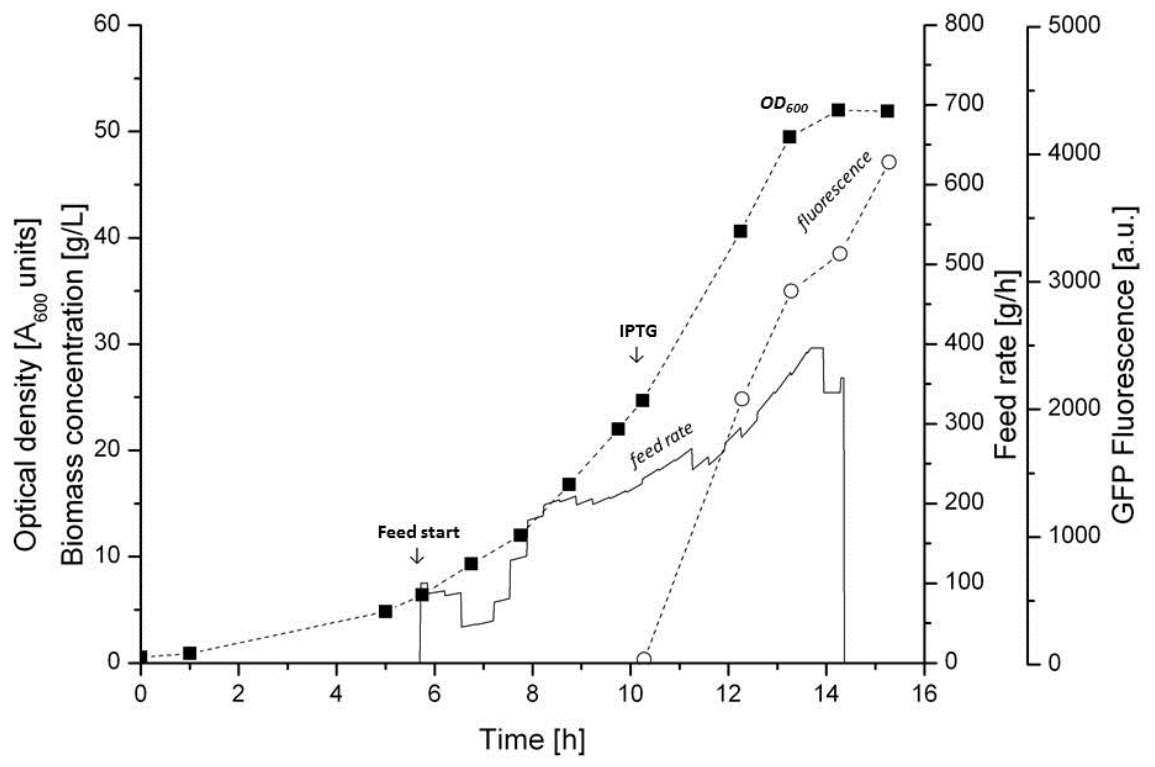




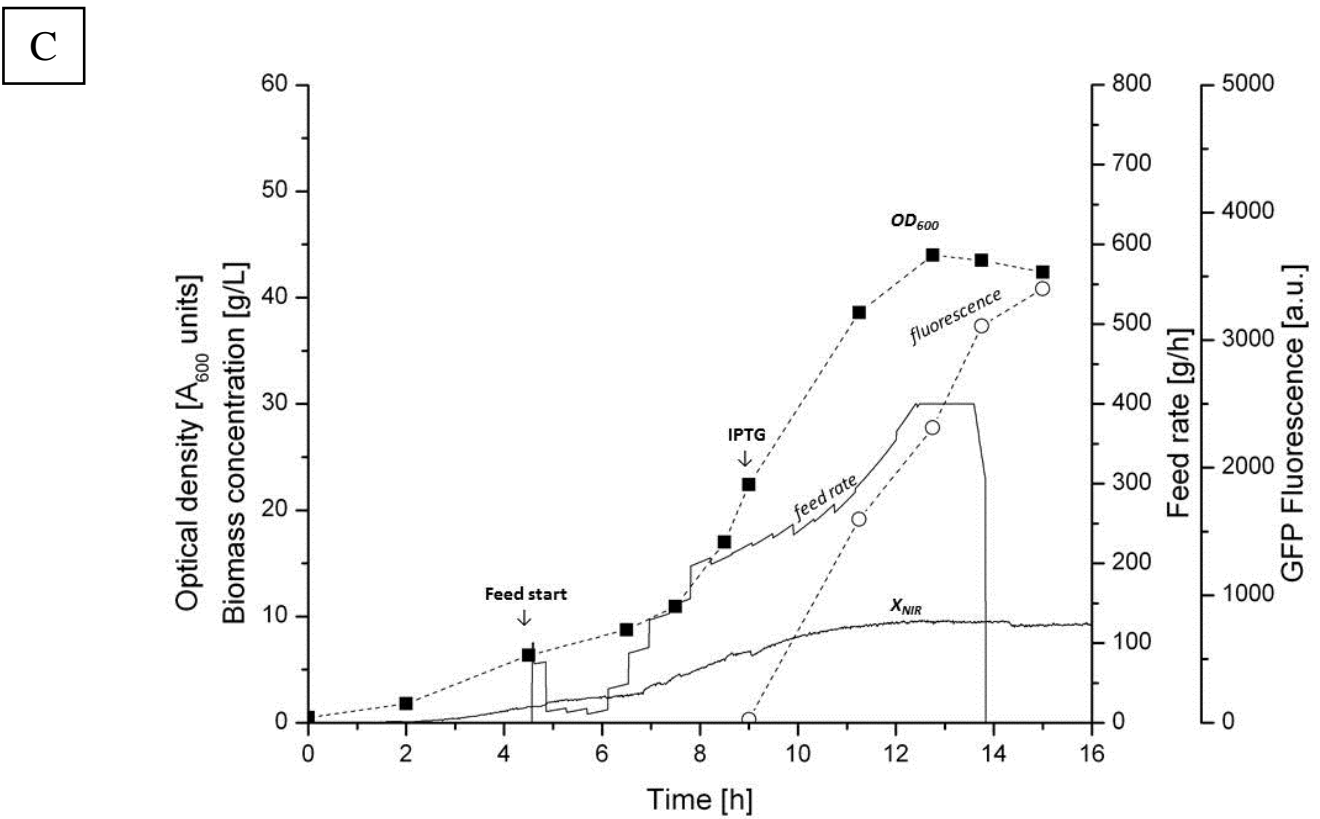

Figure 5

Control of the sum of MAF metabolite concentrations in the fed-batch GFP cultivation. Feeding starts at $5 \mathrm{~h}$ and induction is carried out at 9-10 $\mathrm{h}$ using $0.03 \mathrm{~g} \mathrm{~L}^{-1}$ IPTG. Figures (A) (B) and (C) show three cultivations with identical control settings. (Data for biomass concentration from NIR measurements in B is not available). 
A
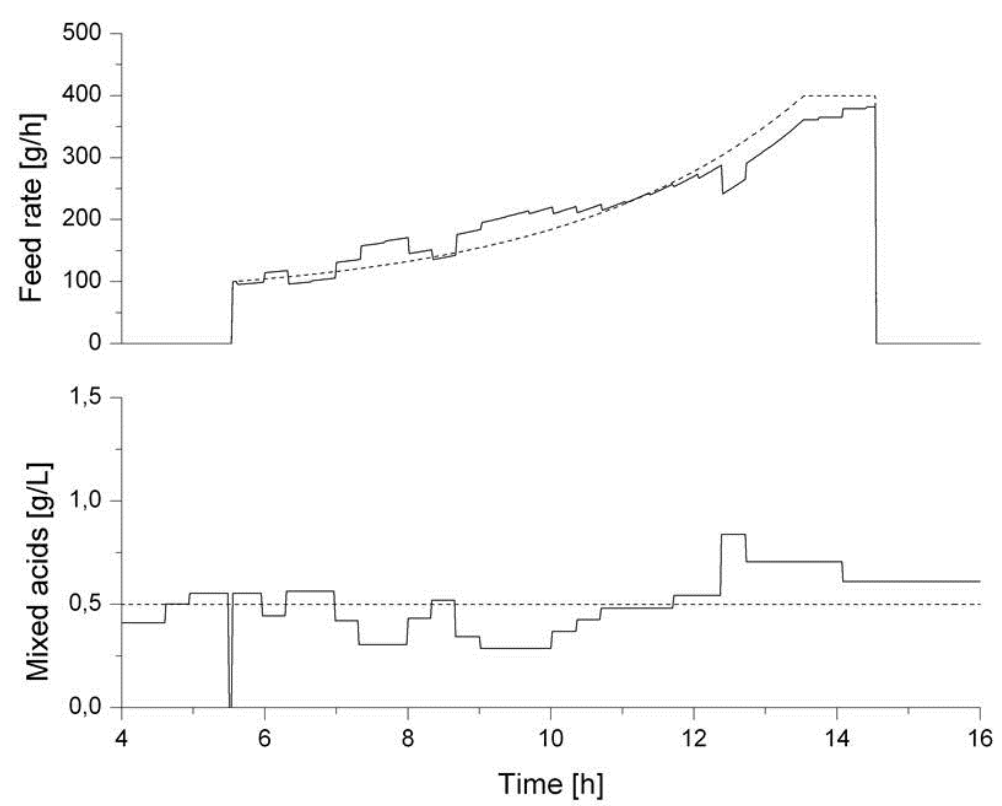

B
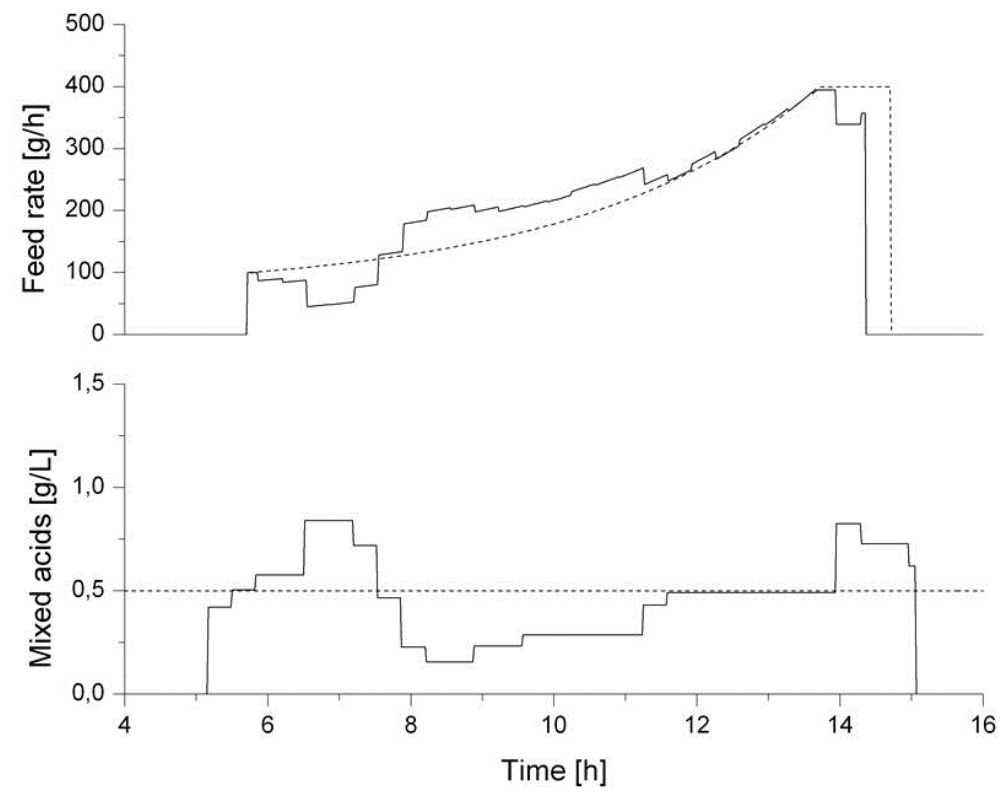


\section{$\mathrm{C}$}
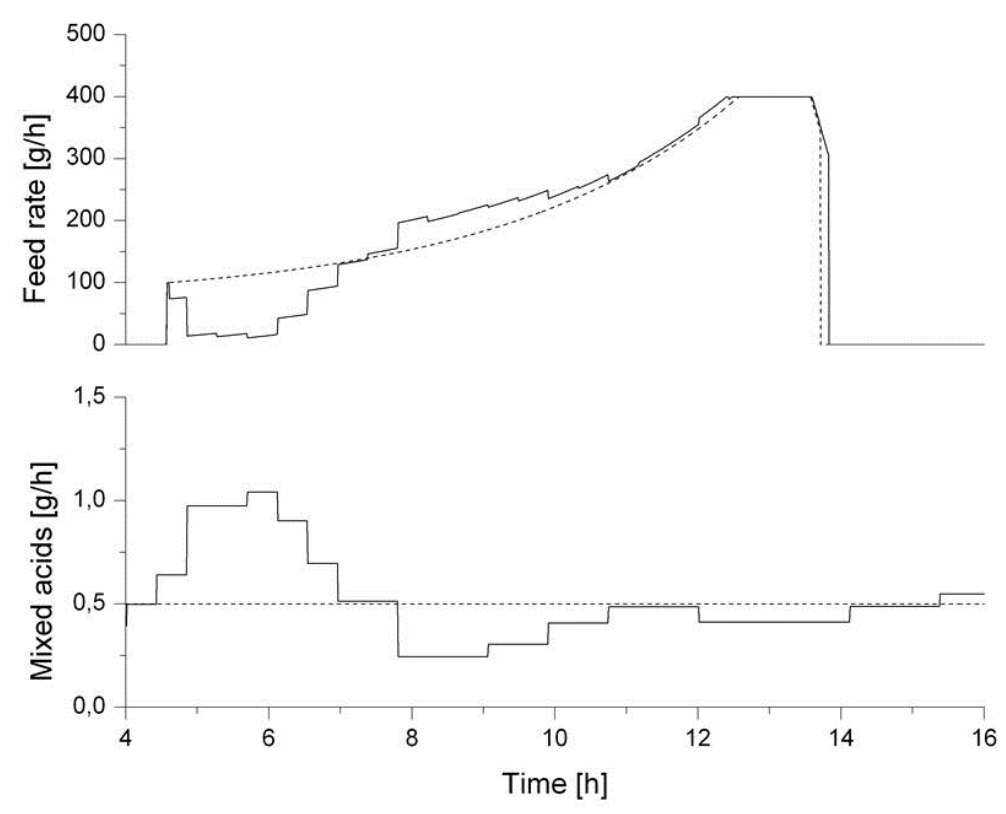

Figure 6

Control of the feed rate according to the sum of the MAF metabolite concentrations (acetate, lactate, formate, ethanol) for the same three cultivations as shown in Figure 5. The upper panels show the regulatory effect of the feed rate controlled by the concentrations of the sum of the MAF metabolite concentrations shown in the lower panels. The dotted line is the preset feeding profile. 